\title{
Media independence, political agendas, and a world-class medical journal: Defining the dispute at the CMAJ
}

$\mathrm{T}$ he CMAJ, recognized as the fifth leading medical journal in terms of international impact in the world today ${ }^{1}$, is in crisis.

In February 2006, the Canadian Medical Association (CMA) fired the CMAJ editor-in-chief, Dr. John Hoey, and senior deputy editor, Anne Marie Todkill. In the weeks that followed, additional editors, including the majority of the editorial board, resigned.

The main issue in this crisis seems to be editorial independence although stakeholders have largely kept quiet regarding the exact details. The CMAJ includes more than peer-reviewed medical research as it also publishes editorials, news, letters, and investigative pieces. Thus, the journal has the potential to generate controversy among the many stakeholders in the medical community.

In 2001 and 2002, two separate editorials received disapproval from the CMA. The first editorial supported the medical use of marijuana, contradicting the CMA's official position. The second editorial criticized Quebec physicians for not staffing an Emergency Department that lead to the death of a man forced to travel to an alternate hospital 30 minutes away. The CMA president demanded a retraction of the latter article. In response, the CMAJ editorial board allegedly told the CMA that they were threatening the journal's editorial independence. ${ }^{2}$

In November 2005, the CMAJ editorial board once again upset the association regarding a news report on Plan B, the emergency contraception pill that just gained over-the-counter sales status. Subsequent to this change in status, a writer for the CMAJ recruited a cohort of women to study their satisfaction with pharmacist provision of the drug and reported that some pharmacists were asking women for personal health information. ${ }^{3}$ The Canadian Pharmacists Association found out about the news report and objected to the article.
As a result, Graham Morris, president of CMA Media Inc (CMAJ's publisher), informed Hoey not to publish the report, stating that the women's observations could be considered research of which had not been ethically approved by the journal. The editor removed some of the women's comments and published a revised version of the article. ${ }^{4}$ Those changes marked the first time (we know of) an editor changed its content at the request of the publisher.

A few months later, the journal published an unfavorable profile of the new federal health minister, Tony Clement, on its website two weeks before CMA board members were to meet Minister Clement. Morris requested the story be removed from the internet. A reporter then inserted positive remarks from the CMA president before reposting it. ${ }^{4}$

One week later, Hoey and Todkill were fired. Morris stated that the firings had nothing to do with specific stories or editorials. ${ }^{5}$ In any case, just days later, an ad-hoc committee of the CMAJ editorial board concluded that the journal's editorial autonomy is largely an illusion. ${ }^{4}$

On March 7, the CMA appointed a retired Supreme Court chief justice, Antonio Lamer, to review the future governance structure of the journal.

Editorial independence is not a novel ideal. It has a long and resonant history in Canada. It's the reason why there is such respect and admiration for Joseph Howe, the original warrior of media independence in Canada. The idea of editorial independence is to prevent media from succumbing to pressure from governments and powerful (financing) organizations. In terms of a medical journal, editorial independence means the publication does not have to yield to the large health-related political pressures facing health care associations today. Like all media with editorial 
independence, it can voice critical, minority, and controversial opinions.

Let me tell you a story.

In 2000, the Asper family of Winnipeg (owners of CanWest Global Communications Corp.) purchased the majority of Conrad Black's newspapers in Canada. Shortly after the acquisition, which included 13 major dailies across the country, the family expressed their pro-Liberal and pro-Israeli views with newspaper staff. When reporters and editors expressed opinions differing from those of the family, articles were reworded or omitted, and journalists were fired without explanation or resigned.

In September 2004, a reader of one of CanWest's papers - the Ottawa Citizen - wrote a letter to the editor that the paper had changed a number of words in an Associated Press (AP) story from Iraq. The AP story used the words "insurgents" and "fighters." In the Citizen-run story, the words were "terrorists."

Editing wire copy from international news agencies, such as AP, was a new CanWest policy for all its papers.

In the very same September paper carrying the letter to the editor, an AP story from Jerusalem indicated that an Israeli missile had killed three "terrorists" linked to Yasser Arafat's Fatah movement. In the original article, three "terrorists" were not killed; rather, three "people" were. ${ }^{6}$

If we disapprove of CanWest's editorial interference to satisfy a rather narrow world view, why then would we be fine with the CMA changing a story on Minister Clement to fit an apparently political agenda?

Is the CMAJ a political mouthpiece for the CMA, or is it an independent forum to deliver, discuss, and debate health care news, issues, policy, and research?

From the recent flurry of resignations, it would appear as though many on the editorial board viewed the journal as the latter - a highly-respected national, independent journal, of the same caliber as the New England Journal of Medicine, the Brit- ish Medical Journal, and The Lancet, three journals independent from their financing associations.

Determining the clear purpose of the CMAJ is amongst the questions that need to be answered before this current situation can be laid to rest.

Note from Editor: Just before this issue was printed the May 13th, 2006 issue of the BMJ reported that Justice Lamer stepped down from his role due to unspecified and unforeseen health circumstances.

\section{Robin Gillingham}

\section{References}

1. Proctor G (2003). CMAJ's impact factor rises in 2002. CMAJ; 169(4):325.

2. Shuchman, M, Redelmeier, DA. Politics and independence - the collapse of the Canadian Medical Association Journal. NEJM; 354(13):1337-1339.

3. Eggertson L, Sibbald B. (2005). Privacy issues raised over Plan B: women asked for names, addresses, sexual history. CMAJ; 173(12):1435-6.

4. Kassirer JP, Davidoff F, O'Hara K, Redelmeier DA. "Editorial Autonomy of CMAJ." CMAJ. 16 Mar. $2006<$ http://www.cmaj.ca/cgi/rapidpdf/ cmaj.060290v1>.

5. "The CMAJ Firings: Crisis At Canada'S Most Influential Medical Journal." CBC News Online. 17 Mar. 2006. 3 Apr. $2006<$ http://www.cbc.ca/news/ background/journalism>.

6. Kimber, S. (2005). The wonderful world of Iz...is 1984 all over again. From Silenced: International Journalists Expose Media Censorship. David Dadge (Ed). Prometheus Books: New York.

\section{Instructions for authors}

$$
\begin{gathered}
\text { Please visit } \\
\text { http://edmj.medicine.dal.ca } \\
\text { for instructions on } \\
\text { submitting to the DMJ. }
\end{gathered}
$$

